\title{
Entwistle's Epistemology: Job Coaching for Meaning
}

\author{
Anthony Shay* \\ University of Wisconsin-Stout Vocational Rehabilitation Institute, USA
}

Submission: February 28, 2017; Published: March 06, 2017

*Corresponding author: Anthony Shay, University of Wisconsin-Stout Vocational Rehabilitation Institute, 202 Washington St., Westby, WI 54667, USA, Tel: 608-606-2459; Email: tafts4268@gmail.com

\section{Introduction}

According to Noel Entwistle, effective knowledge transformation hinges on several considerations:

a) Broad conceptual mapping onto practical experiences.

b) Language accessibility.

c) Reflection regarding practical applications.

d) Consideration of beneficial improvements to applications.

e) Theoretical framework "pedagogical fertility" (conceptual validity, relative simplicity, metaphorical power, and student engagement (2000, p. 1) [1].

Although Entwistle's model was developed based on student learning in higher education, he finds relevance for the model beyond this context. He finds that the developmentally-based level of learning a student achieves markedly impacts the approach they take in learning new tasks. This model offers a viable approach to the field of vocational rehabilitation toward conceptualizing learning and meaning for consumers with disabilities in employment.

\section{Discussion}

Entwistle suggests four fundamental approaches to learning: deep, strategic, surface, and apathetic learning. These approaches to learning represent a continuum of learning from the more comprehensive and in-depth approach to a more superficial, rote memorization approach to learning. These strategies vary in terms of the depth of learning that takes placedeep learning being the most integrated learning and apathetic involving only a "bits-and-pieces" approach to internalizing information. Competence in using a particular approach is context dependent: "an approach, strictly speaking, can only be applied with any confidence to a particular teaching-learning environment, as the approach is the result of an interaction between the student and that context" (2000, p.4) [3].

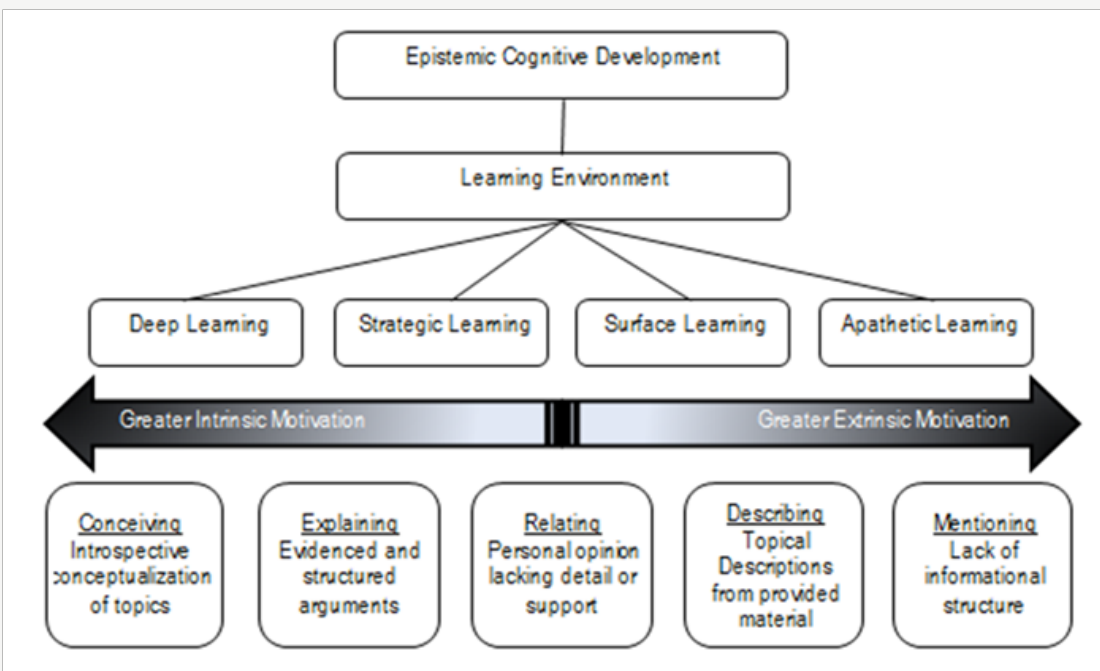

Figure 1: Client developmental approach to learning. Adapted from Entwistle, 2000 [2]. 


\section{Global Journal of Addiction \& Rehabilitation Medicine}

Furthermore, Entwistle posits learning outcomes levels as measures of understanding. These include mentioning, describing, relating, explaining, and conceiving, each of which in turn represent greater learner comprehension (2000, p. 4) [4]. Three stable elements comprise what he terms as a disposition to understand for oneself: intentional learning processes, motivation to apply oneself to the learning process effectively, and presence of mind and orientation to the context of learning. This disposition toward thinking is characterized by an organized and disciplined approach marked by effort- a drive for cognitive development [5]. Functional impairments may restrict learning strategies. The depth of learning may be a function of the capacity for abstract thinking. Client attitude, learning habits, and learning contexts are important considerations [6]. As such it behooves vocational rehabilitation professionals to be vigilant regarding the depth of learning they observe as they mediate meaning for and with their clientele. Figure 1 illustrates the approaches to learning and internalization and depth of the learning experience.

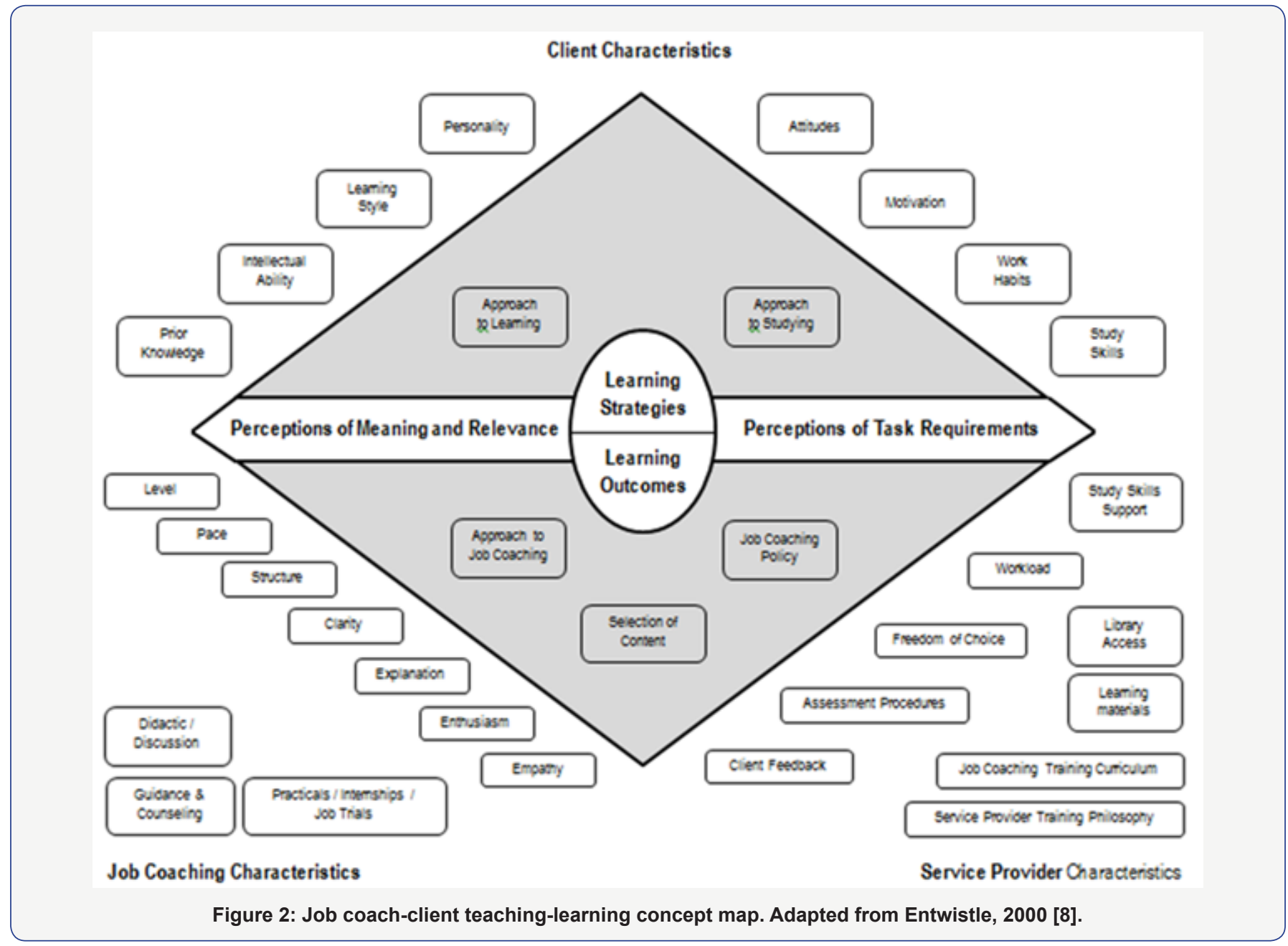

The subjective experience of job coaching from the perspective of the client is a product of a multitude of variables both inherent in the client and extrinsic to them. Figure 2 illustrates the interrelationship between the internal and external variables which comprise the job coaching-client experience. The top half of the figure represents the clientfocused variables and the bottom half those of the job coach and service provider. Client perception of coaching service provision drives their choice of learning approach (with consideration to developmental capacity and epistemic cognition) albeit in an inconsistent manner. A job coach must bridge the gap between their personal understanding with that of the target understanding as well as the historical and proximal influences on both themselves and their clients (Entwistle, 2000, p. 8) [7].

This gap represents their understanding of the established standards for coaching (set by the service provider facilitating job coaching, vocational rehabilitation, or some other authority), their prior knowledge and experience (e.g. education, cultural context/history), and pedagogy (subject matter expertise and how to teach it). The measurement of the client's understanding of the subject matter is made against the job coach's understanding of the material as established by the target understanding set by the coach. 
NOTE: The variables in the lower left quadrant of Figure 2- level, pace, structure, clarity, explanation, enthusiasm, and empathy refer to the training aspect of coaching and to characteristics of the job coach not the work tasks or the client performing them.

\section{Conclusion}

Epistemological (i.e. cognitive) development and environment determine a job coaching client's learning approach, motivational intention, and learning depth. Personal and target understanding with historical and proximal influences "together...influence the strategies... [a client] adopts, the levels of effort and engagement employed, and hence the level of understanding reached" (p. 9) [9]. Vocational rehabilitation professionals must account for these variables toward building vocational meaning for clients and effective service delivery. Effectiveness is jeopardized whenever this process is poorly negotiated. For Entwistle (2000) [10], teaching necessarily involves a collaborative approach to learning whereby the teacher (job coach) is also learning.

\section{References}

1. Entwistle N (2000) Promoting deep learning through teaching and assessment: conceptual frameworks and educational contexts. In TLRP conference, Leicester

2. Entwistle N (2000) Promoting deep learning through teaching and assessment: conceptual frameworks and educational contexts. In TLRP conference, Leicester.
3. Entwistle N (2000) Promoting deep learning through teaching and assessment: conceptual frameworks and educational contexts. In TLRP conference, Leicester.

4. Entwistle N (2000) Promoting deep learning through teaching and assessment: conceptual frameworks and educational contexts. In TLRP conference, Leicester.

5. Entwistle N, McCune V (2013) The Disposition to Understand for Oneself at University: Integrating Learning Processes with Motivation and Metacognition. British Journal of Educational Psychology 83(2): 267-279.

6. McCune V, Entwistle N (2000) The deep approach to learning: analytic abstraction and idiosyncratic development. In Innovations in Higher Education Conference (Vol. 30), Helsinki: University of Helsinki.

7. Entwistle N (2000) Promoting deep learning through teaching and assessment: conceptual frameworks and educational contexts. In TLRP conference, Leicester.

8. Entwistle N (2000) Promoting deep learning through teaching and assessment: conceptual frameworks and educational contexts. In TLRP conference, Leicester.

9. Entwistle N (2000) Promoting deep learning through teaching and assessment: conceptual frameworks and educational contexts. In TLRP conference, Leicester.

10. Entwistle N (2000) Promoting deep learning through teaching and assessment: conceptual frameworks and educational contexts. In TLRP conference, Leicester.

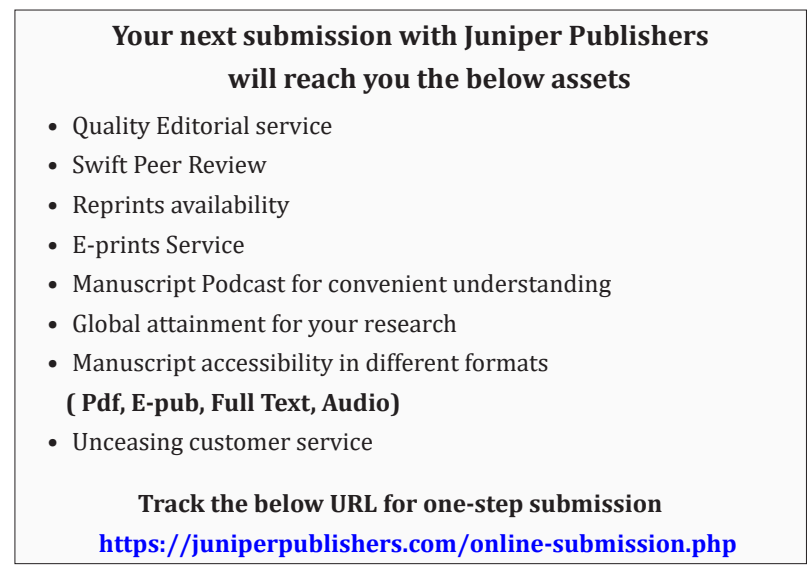

